\title{
Hormones and Genes of Importance in Bone Physiology and Their Influence on Bone Mineralization and Growth in Turner Syndrome
}

\section{A Summary of the Joint Symposium between the Bone, Growth Plate and Turner Syndrome Working Groups of the European Society for Paediatric Endocrinology}

\author{
Anenisia C. Andrade ${ }^{a}$ Jeffrey Baron ${ }^{b}$ Stavros C. Manolagas ${ }^{c}$ Nick J. Shaw ${ }^{d}$ \\ Gudrun A. Rappold ${ }^{f}$ Malcolm D.C. Donaldson ${ }^{e}$ Emma Jane Gault ${ }^{\mathrm{e}}$ \\ Lars Sävendahla \\ a Department of Women's and Children's Health, Karolinska Institutet, Stockholm, Sweden; b Section on Growth \\ and Development, NICHD, National Institutes of Health, Bethesda, Md., 'C Center for Osteoporosis and Metabolic \\ Bone Diseases and Central Arkansas Veterans Healthcare System, University of Arkansas for Medical Sciences, \\ Little Rock, Ark., USA; ${ }^{d}$ Department of Endocrinology, Birmingham Children's Hospital, Birmingham, and \\ e Department of Child Health, Royal Hospital for Sick Children, Glasgow, Strathclyde, UK; \\ ${ }^{f}$ Department of Human Molecular Genetics, University of Heidelberg, Heidelberg, Germany
}

\section{Key Words}

Bone $\cdot$ Growth $\cdot$ Turner syndrome $\cdot \mathrm{SHOX} \cdot$ Wnt •

Oxandrolone $\cdot$ Estrogen

\begin{abstract}
This mini review summarizes papers presented in a Joint Symposium between the Bone, Growth Plate and Turner Syndrome Working Groups of the European Society for Paediatric Endocrinology (ESPE) that was held on September 9, 2009, in New York. The program had been composed to give an update on hormones and genes of importance in bone physiology and their influence on bone mineralization and growth in Turner syndrome. This paper summarizes the data and highlights the main topics and discussions related to each presentation.

Copyright $\odot 2010$ S. Karger AG, Basel
\end{abstract}

\section{Bone Development, Growth, and Structure}

Dr. Jeffrey Baron from the NIH described how longitudinal bone growth takes place at the growth plate, a specialized layer of cartilage located at the ends of the long bones, in a process called endochondral ossification. The epiphyseal plate is formed by three zones that represent distinct stages of chondrocyte differentiation. In the resting zone, stem-like cells proliferate at a low rate and are capable of renewing the pool of proliferative chondrocytes [1]. In the proliferative zone, chondrocytes proliferate at a high rate, and the newly formed cells line up along the long axis of the bone, forming columns of cells that direct growth primarily in one dimension. In the hypertrophic zone, chondrocytes cease proliferating, increase in size, and produce a calcified matrix rich in type $\mathrm{X}$ collagen. The terminally differentiated hypertrophic chondrocytes produce factors that attract blood vessels and bone cells from the adjacent metaphysis which remodel the newly formed cartilage into trabecular bone. Chon-

\section{KARGER \\ Fax +4161306 1234 \\ E-Mail karger@karger.ch}

www.karger.com
(C) 2010 S. Karger AG, Basel

$1663-2818 / 10 / 0733-0161 \$ 26.00 / 0$

Accessible online at:

www.karger.com/hrp
Anenisia C. Andrade, MD

Pediatric Endocrinology Unit, Q2:08, Department of Woman and Child Health Karolinska Institutet and Karolinska University Hospital

SE-171 76 Stockholm (Sweden)

Tel. +46085177 6530, Fax +46085177 5128, E-Mail anenisia.andrade@ki.se 
drocyte regulation is complex and involves both endocrine signals (e.g., GH, estrogen, and thyroid hormone), and local/paracrine signals (e.g., PTHrP/Ihh, BMPs, IGFs, Wnts and VEGF). During childhood, major developmental changes occur in the skeletal system. The growth plate undergoes programmed senescence, causing growth to slow. Growth plate senescence is not caused by changes in any known systemic factor. Instead, growth plate senescence appears to be caused by a mechanism intrinsic to the growth plate and to be a function, not of time per se, but rather of growth [2]. In adolescence, epiphyseal fusion is triggered when growth plate chondrocytes have exhausted their proliferative capacity, and thus fusion is a consequence, not a cause, of growth cessation. Estrogen accelerates growth plate senescence and thus secondarily hastens epiphyseal fusion. Long bones increase not only in length, but also in diameter. This process occurs by intramembranous bone formation at the periosteal surface and is combined with bone resorption at the endosteal surface, which enlarges the medullary cavity. In addition to this bone modeling, the childhood skeleton also undergoes bone remodeling, which persists into adulthood. Both animal and clinical studies suggest that bone mineral acquisition during childhood may have little effect on bone density in late adulthood because the juvenile bone is largely replaced over time through modeling and remodeling [3].

\section{Oxidative Stress in the Pathogenesis of Bone Metabolic Disorders}

Dr. Stavros C. Manolagas presented several lines of evidence suggesting that organismal aging per se, rather than an age-associated failure of other organs and tissues, may be the predominant mechanism of the bone fragility disease. In contrast to the conventional thinking that loss of estrogens at menopause is the seminal mechanism of osteoporosis, bone loss begins as early as the early part of the third decade in both women and men [4], and age is a more critical determinant of bone fracture risks than bone mass itself [5]. Consistent with these clinical observations, mechanistic studies in mice show that aging, and specifically increased oxidative stress, is a fundamental pathogenetic mechanism of age-related bone loss and strength, leading to, among other changes, a decrease in osteoblast lifespan and bone formation. Oxygen radicalinduced activation of the FoxO family of transcription factors defends against such an increase by upregulating free radical scavenging and DNA repair enzymes, there- by representing an indispensable homeostatic mechanism for skeletal health [6]. Consistent with this, Dr. Manolagas presented not yet published data showing that mice lacking FoxO1, FoxO3, and FoxO4, the three principal members of the FoxO family, promote an increase in oxidative stress, osteoblast apoptosis, and decreases bone mass. It has been extensively documented that the $\mathrm{Wnt} / \beta$-catenin signaling pathway is a critical determinant of bone mass, by stimulating osteoblastogenesis and suppressing osteoblast apoptosis and osteoclastogenesis $[7,8]$. Wnts are secreted proteins that bind to a Frizzled receptor and a low density lipoprotein receptor-related protein 5 (LRP5) or LRP6 co-receptor, resulting in a rise in the level of $\beta$-catenin by preventing its degradation by the proteasome [9]. Binding of $\beta$-catenin to members of the TCF family converts them from repressors to activators of a variety of genes, including those involved in the differentiation and survival of osteoblasts. Importantly, $\beta$-catenin is also an essential partner of the FoxO family of transcription factors, and oxidative stress compromises $\beta$-catenin/TCF-mediated transcription and osteoblastogenesis because of competition between FoxO and TCF for a limited pool of $\beta$-catenin [10]. Such competition for $\beta$-catenin may explain how the increased oxidative stress that occurs with advancing age leads to a deficit in osteoblast number. Therefore, the decline of $\beta$-catenin below the critical threshold required for FoxO-dependent transcription of antioxidant enzymes could further amplify lipoxygenase-induced oxidative stress. Fascinatingly, attenuation of Wnt-mediated transcription, resulting from an autosomal dominant missense mutation in LRP6 or LRP5 co-receptors for the Wnt-signaling pathway, has been linked recently genetically not only to premature osteoporosis, but also to coronary artery disease as well as several features of the metabolic syndrome including hyperlipidemia, hypertension, and diabetes, but not obesity [11]. Hence, antagonism of Wnt signaling by oxidative stress-induced activation of FoxOs with increasing age may be a common molecular mechanism contributing to the development not only of involutional osteoporosis, but several degenerative diseases during the process of aging.

\section{SHOX Gene Impact on Cartilage Development and Bone Growth}

Dr. Gudrun A. Rappold highlighted that the SHOX gene represents a disease locus for short stature in the human pseudoautosomal regions of sex chromosomes. 
SHOX encodes a homeodomain transcription factor responsible for a significant proportion of longitudinal bone growth, with a dose-dependent association between the number of active copies of the SHOX gene and height, such that SHOX haploinsufficiency is associated with short stature, whereas SHOX overdose as seen in sexchromosome polyploidy is associated with tall stature [12]. Patients with mutations or deletions of SHOX (or its enhancers), including those with Turner syndrome and Leri-Weill dyschondrosteosis who are haploinsufficient for SHOX, have variable degrees of growth impairment, with or without a spectrum of skeletal anomalies consistent with dyschondrosteosis [13]. Also, between 5 and $10 \%$ of patients diagnosed with idiopathic short stature are haploinsufficient for SHOX and of those, about a quarter have an enhancer defect [14]. SHOX is expressed in human growth plate cartilage already early in prenatal life, neonatally and also during puberty $[15,16]$. A comparative functional analysis of mutant and wild-type SHOX indicated that SHOX expression leads to cell cycle arrest and apoptosis suggesting a role of SHOX in hypertrophic chondrocyte differentiation [15]. These events are associated with upregulation in the expression of several genes including the cyclin kinase inhibitors p21 and p27, which have been previously described to regulate chondrocyte differentiation and, as SHOX, are particularly highly expressed in terminally differentiated chondrocytes [17]. In addition, SHOX targets NPPB which encodes the natriuretic peptide BNP. Binding of SHOX to the NPPB promoter was demonstrated in vivo by chromatin fixation and immunoprecipitation and lack of promoter activation was shown in two SHOX mutants from patients with Leri-Weill syndrome [18]. Thus, SHOX and BNP act on the same pathway in bone development. The closely related paralogous gene of SHOX, termed SHOX2, shares an identical homeodomain. It also functions as a key regulator of endochondral ossification and regulates Runx2, an important regulator of chondrogenesis [19]. Altogether, these findings suggest that SHOX plays a role in chondrocyte function in the growth plate as a regulator of cellular differentiation and viability, and relates these cellular events to the phenotypic consequences of SHOX deficiency [15].

\section{Bone Health in Turner Syndrome}

Dr. Nick J. Shaw highlighted that girls with Turner syndrome (TS) have been described to have decreased bone density (BD) and bone strength [20]. However, many of the early studies that utilized dual-energy X-ray absorptiometry (DXA) of the lumbar spine did not correct for short stature leading to an overdiagnosis of osteoporosis. This is because DXA is affected by bone size and thus height. It measures areal $\mathrm{BD}\left(\mathrm{g} / \mathrm{cm}^{2}\right)$, providing a 2$\mathrm{D}$ projection of a 3-D structure (bone), and it should at least in children be adjusted to provide a volumetric BD $\left(\mathrm{g} / \mathrm{cm}^{3}\right)$. Consequently, subsequent studies that have adjusted BD for body size have not identified a significant problem in the pediatric age group [21]. In addition, it has been shown that adult women with TS and a height $<150$ $\mathrm{cm}$ are likely to be misdiagnosed with osteoporosis when areal $\mathrm{BD}$ is measured, unless adjustments for body size are made [22]. However, some studies that have examined the peripheral skeleton using modalities such as peripheral quantitative computed tomography have suggested a selective deficit in cortical BD and thickness [23] which was felt to be due to a failure of endocortical apposition in response to estrogen. However, another study indicated that a selective deficiency in forearm cortical bone in TS appeared to be independent of ovarian hormone exposure and intrinsic to bone, probably related to X-chromosome gene(s) haploinsufficiency [20]. Estrogen replacement has been shown to be important in optimizing bone mineral accretion with the timing of its introduction being felt to be important [24]. However, there is little current evidence for an increased fracture risk in children and adolescents with TS. There is evidence of an increased risk of fractures in women with TS in the order of $25 \%$, predominantly involving forearm fractures [22]. Regarding growth hormone $(\mathrm{GH})$ treatment, its impact on bone status has been examined with some conflicting results, although the majority does not suggest an additional benefit from $\mathrm{GH}$ treatment. However, today, $\mathrm{rhGH}$ is the standard of care for girls with TS and it is unlikely that placebo-controlled trials will be conducted to address any real effect of rhGH on bone health in TS girls [25]. Dr. Shaw concluded that in view of the lack of evidence for an increased fracture risk and low bone mineral density in pediatric subjects with TS, it is doubtful that it should continue to be listed as a cause of osteoporosis in children. Since the criteria for osteoporosis are not currently fulfilled, routine assessment of BD is not indicated during childhood and adolescence in girls with TS although assessment at the time of transition to adult care is recommended.

Horm Res Paediatr 2010;73:161-165 
Final Height in Turner Syndrome after Oxandrolone and Delayed Pubertal Induction

Researcher Emma Jane Gault firstly gave an overview reminding the audience that short stature is one of the primary features of TS. Although not classically GH-deficient, supraphysiological doses of rhGH increase final height $(\mathrm{FH})$ in girls with TS $[26,27]$. The role of oxandrolone (OX), a non-aromatizable anabolic steroid, in TS remains controversial. When used in combination with rhGH, it has been shown to improve short-term growth velocity, but $\mathrm{FH}$ data are inconclusive $[28,29]$. In addition, some early studies using high doses reported adverse effects such as virilization and advancement of skeletal maturation, although these effects have not been associated with lower doses. However, careful monitoring of patients receiving OX treatment is required. Another common feature of TS is primary ovarian failure causing a delay or absence of pubertal development. Although about $30 \%$ of girls with TS will undergo some spontaneous pubertal development, over $90 \%$ will develop permanent gonadal failure [30]. The optimal age at which to introduce estrogen replacement therapy in TS remains contentious. Some authors advocate delaying pubertal induction in order to prolong the growth period before epiphyseal fusion [31]. However, others cite the positive effect on the cardiovascular, skeletal and reproductive systems, as well as on psychological well-being, of the introduction of estrogen replacement therapy at an earlier, more physiological age. The variable response to rhGH demonstrated by girls with TS, and the continuing uncertainty as to the benefit of OX and the timing of estrogen therapy, emphasizes the need for further research. The UK Turner Study is a randomized, double-blinded and placebo-controlled study, organized by the British Society for Paediatric Endocrinology and Diabetes (BSPED). It examines the impact of OX and the timing of pubertal induction (12 vs. 14 years) with ethinyl estradiol $\left(\mathrm{E}_{2}\right)$ therapy in a group of girls with TS. The primary outcome measure is FH. All participants received a standard dose of GH (10 mg/m²/week given as a daily injection) and all were randomized to either OX $(0.05 \mathrm{mg} / \mathrm{kg} / \mathrm{day}$; maximum daily dose $2.5 \mathrm{mg}$ ) or placebo at 9 years of age (or from enrolment if age $>9$ years). Participants requiring estrogen therapy (i.e. excluding those with spontaneous puberty) were further randomized to either begin oral $\mathrm{E}_{2}$ for pubertal induction at 12 years (year 1: $\mathrm{E}_{2} 2 \mu \mathrm{g}$ daily; year 2: $E_{2} 4 \mu$ g daily; year 3: 4 months each of $E_{2} 6 / 8 / 10$ $\mu \mathrm{g}$ daily) or to receive placebo for 2 years and then begin estrogen therapy at 14 years of age (same treatment schedule as 12 years group). Girls aged 12-13 years at enrolment were randomized to $\mathrm{OX}$ or placebo on entry to the study but were automatically assigned to begin $\mathrm{E}_{2}$ at 14 years (the so-called 'late group').

Dr. Malcolm D.C. Donaldson presented details of the preliminary analysis of the study. Of the 106 girls recruited between 1999 and 2003, 75 have reached a FH of 151.3 $(S D 6.1) \mathrm{cm}$. Statistical analysis of these preliminary data demonstrates a clear benefit to FH of OX and of pubertal induction at 14 years. However, the interaction between these interventions appears to be negative indicating that there is no additional benefit of treating girls with both OX and late induction. No serious adverse events thought to be attributable to the study medication have been reported; in particular, no voice deepening or clitoromegaly. Additionally, OX has not adversely affected bone maturation in these patients. Finally, examination of height velocity in relation to estrogen status demonstrated a modest pubertal growth spurt in girls with spontaneous puberty. However, this was not replicated in the girls receiving pubertal induction. Further studies are therefore needed to examine alternative treatment regimens for pubertal induction, such as transdermal preparations, which may mimic more closely growth patterns during 'normal' puberty. In conclusion, the data presented suggest that OX treatment is a safe and effective option to improve FH in girls with TS and can be considered a realistic alternative to delayed pubertal induction.

\section{References}

1 Abad V, Meyers JL, Weise M, Gafni RI, Barnes KM, Nilsson O, Bacher JD, Baron J: The role of the resting zone in growth plate chondrogenesis. Endocrinology 2002;143: 1851-1857.

2 Nilsson O, Baron J: Fundamental limits on longitudinal bone growth: growth plate senescence and epiphyseal fusion. Trends Endocrinol Metab 2004;15:370-374.
-3 Gafni RI, Baron J: Childhood bone mass acquisition and peak bone mass may not be important determinants of bone mass in late adulthood. Pediatrics 2007;119(suppl 2): S131-S136.

4 Looker AC, Orwoll ES, Johnston CC Jr, Lindsay RL, Wahner HW, Dunn WL, Calvo MS, Harris TB, Heyse SP: Prevalence of low femoral bone density in older US adults from NHANES III. J Bone Miner Res 1997;12: 1761-1768. 
5 Hui SL, Slemenda CW, Johnston CC Jr: Age and bone mass as predictors of fracture in a prospective study. J Clin Invest 1988;81: 1804-1809.

-6 Kops GJ, Medema RH, Glassford J, Essers MA, Dijkers PF, Coffer PJ, Lam EW, Burgering BM: Control of cell cycle exit and entry by protein kinase B-regulated forkhead transcription factors. Mol Cell Biol 2002;22: 2025-2036.

7 Bodine PV, Zhao W, Kharode YP, Bex FJ, Lambert AJ, Goad MB, Gaur T, Stein GS, Lian JB, Komm BS: The Wnt antagonist secreted frizzled-related protein-1 is a negative regulator of trabecular bone formation in adult mice. Mol Endocrinol 2004;18:12221237.

8 Glass DA 2nd, Bialek P, Ahn JD, Starbuck M, Patel MS, Clevers H, Taketo MM, Long F, McMahon AP, Lang RA, Karsenty G: Canonical Wnt signaling in differentiated osteoblasts controls osteoclast differentiation. Dev Cell 2005;8:751-764.

-9 Glass DA 2nd, Karsenty G: Molecular bases of the regulation of bone remodeling by the canonical Wnt signaling pathway. Curr Top Dev Biol 2006; 73:43-84.

10 Almeida M, Han L, Martin-Millan M, O'Brien CA, Manolagas SC: Oxidative stress antagonizes Wnt signaling in osteoblast precursors by diverting $\beta$-catenin from T-cell factor- to forkhead box O-mediated transcription. J Biol Chem 2007;282:2729827305.

11 Manolagas SC, Almeida M: Gone with the Wnts: $\beta$-catenin, T-cell factor, forkhead box $\mathrm{O}$, and oxidative stress in age-dependent diseases of bone, lipid, and glucose metabolism. Mol Endocrinol 2007;21:2605-2614.

-12 Ogata T, Matsuo N, Nishimura G: SHOX haploinsufficiency and overdosage: impact of gonadal function status. J Med Genet 2001;38:1-6.

13 Rappold G, Blum WF, Shavrikova EP, Crowe BJ, Roeth R, Quigley CA, Ross JL, Niesler B: Genotypes and phenotypes in children with short stature: clinical indicators of SHOX haploinsufficiency. J Med Genet 2007;44: 306-313.
14 Chen J, Wildhardt G, Zhong Z, Roeth $\mathbf{R}, 2$ Weiss B, Steinberger D, Decker J, Blum WF, Rappold GA: Enhancer mutations of the SHOX gene as a frequent cause of short stature - the essential role of a $250-\mathrm{kb}$ downstream regulatory domain. J Med Genet 2009.

15 Marchini A, Marttila T, Winter A, Caldeira2 S, Malanchi I, Blaschke RJ, Hacker B, Rao E, Karperien M, Wit JM, Richter W, Tommasino M, Rappold GA: The short stature homeodomain protein SHOX induces cellular growth arrest and apoptosis and is expressed in human growth plate chondrocytes. J Bitor 2 Chem 2004:279:37103-37114.

16 Munns CJ, Haase HR, Crowther LM, Hayes MT, Blaschke R, Rappold G, Glass IA, Bat 2 JA: Expression of SHOX in human fetal and childhood growth plate. J Clin Endocrinol Metab 2004;89:4130-4135.

17 Ballock RT, Zhou X, Mink LM, Chen D 27 Mita BC, Stewart MC: Expression of cyclindependent kinase inhibitors in epiphyseal chondrocytes induced to terminally diffe-28 entiate with thyroid hormone. Endocrinology 2000;141:4552-4557.

18 Marchini A, Hacker B, Marttila T, Hesse V, Emons J, Weiss B, Karperien M, Rappold G: $\mathrm{BNP}$ is a transcriptional target of the short stature homeobox gene SHOX. Hum Mol Genet 2007;16:3081-3087.

19 Cobb J, Dierich A, Huss-Garcia Y, Duboule D: A mouse model for human short-stature syndromes identifies Shox2 as an upstream regulator of Runx2 during long-bone development. Proc Natl Acad Sci USA 2006;103: 4511-4515.

20 Bakalov VK, Axelrod L, Baron J, Hanton L, Nelson LM, Reynolds JC, Hill S, Troendle J, Bondy CA: Selective reduction in cortidel 30 bone mineral density in Turner syndrome independent of ovarian hormone deficiency. J Clin Endocrinol Metab 2003;88:57175722.

21 Shaw NJ, Rehan VK, Husain S, Marshall T, Smith CS: Bone mineral density in Turner's syndrome - a longitudinal study. Clin Endocrinol (Oxf) 1997;47:367-370.

-22 Gravholt CH, Vestergaard P, Hermann AP, Mosekilde L, Brixen K, Christiansen JS: Increased fracture rates in Turner's syndrome: a nationwide questionnaire survey. Clin Endocrinol (Oxf) 2003;59:89-96.
Bechtold S, Rauch F, Noelle V, Donhauser S, Neu CM, Schoenau E, Schwarz HP: Musculoskeletal analyses of the forearm in young women with Turner syndrome: a study using peripheral quantitative computed tomography. J Clin Endocrinol Metab 2001;86:58195823

Hogler W, Briody J, Moore B, Garnett S, Lu PW, Cowell CT: Importance of estrogen on bone health in Turner syndrome: a crosssectional and longitudinal study using dualenergy x-ray absorptiometry. J Clin Endocrinol Metab 2004;89:193-199.

Bakalov VK, Bondy CA: Fracture risk and bone mineral density in Turner syndrome. Rev Endocr Metab Disord 2008;9:145-151.

Guyda HJ: Four decades of growth hormone therapy for short children: what have we achieved? J Clin Endocrinol Metab 1999;84: 4307-4316

Haeusler G: Growth hormone therapy in patients with Turner syndrome. Horm Res 1998;49(suppl 2):62-66.

8 Stahnke N, Keller E, Landy H: Favorable final height outcome in girls with UllrichTurner syndrome treated with low-dose growth hormone together with oxandrolone despite starting treatment after 10 years of age. J Pediatr Endocrinol Metab 2002;15: 129-138.

9 Nilsson KO, Albertsson-Wikland K, Alm J, Aronson S, Gustafsson J, Hagenas L, Hager A, Ivarsson SA, Karlberg J, Kristrom B, Marcus C, Moell C, Ritzen M, Tuvemo T, Wattsgard C, Westgren U, Westphal O, Aman J: Improved final height in girls with Turner's syndrome treated with growth hormone and oxandrolone. J Clin Endocrinol Metab 1996; 81:635-640.

Bondy CA: Care of girls and women with Turner syndrome: a guideline of the Turner syndrome study group. J Clin Endocrinol Metab 2007;92:10-25.

1 Cacciari E, Mazzanti L: Final height of patients with Turner's syndrome treated with $\mathrm{GH}$ : indications for GH therapy alone at high doses and late estrogen therapy. Italian Study Group for Turner Syndrome. J Clin Endocrinol Metab 1999;84:4510-4515. 